\title{
Undertaking Bioequivalence Studies: The Challenges and Way Forward
}

\author{
Ahmad Hassali MA ${ }^{1}$ and Eldin Munsour E2* \\ ${ }^{1}$ Professor of Social and Administrative Pharmacy, University of Science, Malaysia \\ ${ }^{2}$ Pharmacy and Drug Control Department, University of Science, Malaysia
}

Submission: March 27, 2017; Published: May 30, 2017

*Corresponding author: Emad Eldin Munsour, Pharmacy and Drug Control Department, School of Pharmaceutical Sciences, University of Science, Malaysia, Email: emadkirra@gmail.com

\section{Introduction}

The vision of most of the national drug regulatory agencies (NRAs) around the globe is to grant the marketing authorization (MA) to medicinal product(s), which has three essential characteristics "Safety, Efficacy and Quality". Two of the three PILLARS characteristics i.e. safety and efficacy are exhibited by providing bioavailability (BA) and/or bioequivalence (BE) studies as per the required guidelines.

The cost, effort and time required for performing BE study for one product is cost-limiting step which considered by most of the generic pharma companies, which require a harmonized requirements across the globe. Different region or country has different requirement for submission of bioequivalence study. The submission is accompanied by a list of approved contract research organizations (CROs) which are from which the BE study is accepted. The difference in BE requirements and CROs is quite complicated and not cost effective for the generic industry which is can help to reduce the cost of our medication by around $11 \%$.

The world health organization (WHO) has a list of prequalified CROs which many countries rely on -in addition to the good clinical practice (GCP) by the ICH- can be the foundation work on which most -if not ALL- NRAs can establish mutual recognition of BE studies. The need for BE requirements' harmonization can be explained in the following context:

I. The high cost involved in the design, recruitment and execution of the BE study considering the bioanalytical laboratory (BAL) and clinical pharmacology unit (CPU). For example the cost of BE for oral dosage is between USD 100,000 to 300,000 and more in some other countries [1] . Sample of the test product is from industrial scale batch (or $\geq 1 / 10$ th of production batch or larger or 100,000 units) which is an additional cost to the generic manufacturer. Considering that an between 555 and $639 \mathrm{BE}$ studies are carried out annually [2] this billions of dollars can be saved by considering the magic word "harmonization".

II. A fluctuation in NRA's requirements and guidelines for BE study within a region and even within a country. A recent study exhibited the different approaches for accepting BE studies by different NRAs for generic topical drug product [3].

III. The times required for submission, compliance and approval of the BE study by independent NRA have huge variation from one NRA to another. The queries received from the NRAs regarding the submitted BE study are diverse and pose additional workload on the sponsor.

IV. The lack of expertise calibers with many NRAs (specially in developing nations) who have appropriate knowledge on critical aspects related to submitted BE study (study design/ protocol, BAL methods and validation, biostatistics analysis and establishment of BE acceptance criteria.

V. International concordance on the comparator drug, harmonization of biowaivers based on biopharmaceutical classification system (BCS) and additional strengths by providing satisfactory in-vitro dissolution kinetic profiles.

VI. The TRIPS agreement by the WTO will pose additional regulatory requirements, as generic manufacturer has to conduct clinical tests in addition to BE study [4]. So considering IMMEDIATE DECISION on global BE harmonization is essential. 
There are pros and cons with regard to the BE requirement. Compliance with BE requirement has led to an increase in the quality of generic drug products resulting in an increase in the competitiveness of country specific manufactured pharmaceuticals for export. This is evidenced by the increasing capability of developing countries pharmaceutical products to be registered with regulatory bodies in many countries. It has also helped to increase the confidence of consumers with regard to their quality and effi cacy. On the other hand, the BE requirement also poses additional challenges for the generic manufacturers. Firstly, the time and cost of developing a product have increased. Secondly, local manufacturers are facing problems of finding centres to conduct BE studies. Centres offering such a service are limited and hence the number of studies conducted by these centres per year is not able to meet demand. Moreover, there are also instances where a generic product has better bioavailability compared to the innovator (above the confi dence interval of 0.8-1.25), and thus fails to meet the BE criteria. Due to the above issues, some smaller generic companies have stopped producing some drug products requiring BE testing, especially when their market share is small. The harmonization of pharma regulatory framework present the pharmaceutical industry with opportunities to penetrate any international market freely. However, this harmonisation opens door for competition in terms of pricing and product quality, which already existed among the generic pharmaceutical manufacturers.

\section{References}

1. Pinheiro Edos S, Bruning K, Macedo MF, Siani AC (2014) Production of antiretroviral drugs in middle-and low-income countries. Antivir Ther 19(Suppl): 3: 49-55.

2. Cook J (2015) Impact of discordance among regulations for biopharmaceutics classification system based waivers of clinical bioequivalence studies. Dissolution Technol 22: 6-10.

3. Braddy AC, Davit BM, Stier EM, Conner DP (2015) Survey of international regulatory bioequivalence recommendations for approval of generic topical dermatological drug products. AAPS J 17(1): 121-133.

4. De Castro T (2011) EU-India TRIPS-plus Agreement: A Real threat for the Developing World. Contemporary European Studies pp. 23-35.

Your next submission with Juniper Publishers will reach you the below assets

- Quality Editorial service

- Swift Peer Review

- Reprints availability

- E-prints Service

- Manuscript Podcast for convenient understanding

- Global attainment for your research

- Manuscript accessibility in different formats

( Pdf, E-pub, Full Text, Audio)

- Unceasing customer service

Track the below URL for one-step submission https://juniperpublishers.com/online-submission.php 